\title{
Flame and Plume Behavior in and near a Corner of Walls
}

WATARU TAKAHASHI and HIROKAZU TANAKA

3-56-2, Nangai, Higashiyamato, Tokyo 207, Japan

OSAMI SUGAWA and MASANORI OHTAKE

Center for Fire Science and Technology

Science University of Tokyo

2641 Yamasaki, Noda, Chiba 278, Japan

\begin{abstract}
The relationship between air entrainment and flame/plume behavior was studied experimentally, when a fire source was placed in and near a corner of vertical walls. Three different sizes of square gas diffusion burners were used, and observation of flame height and measurement of temperature and upward velocity around a corner were carried out. The heat release rate and the separation distance from the wall to the burner were varied as well as the burner size. Mass flow of the plume and air entrainment mass flux are calculated from experimental data, and the effects of air entrainment on flame/plume behavior are quantitatively discussed.
\end{abstract}

KEYWORDS : corner fire, flame height, plume, air entrainment

\section{INTRODUCTION}

Flame height from a square diffusion fire source in a free boundary condition is correlated with the dimensionless heat release rate, $Q^{*}$, which depends on the geometry of the fire source and the potential intensity of the heat release rate. Many researchers have proposed correlations for the flame tip height with $Q^{*}$ [1-5]. In these correlations, the efficiency of reaction is included in the coefficient of $Q^{*}$, since it is assumed that sufficient air is entrained into the reaction zone and the whole fuel released from the source reacts perfectly. In other words, the function, which indicates the character of combustion in the reaction zone, is given as a constant number. When air entrainment is restricted physically and/or chemically, however, the flame and plume properties changed 
remarkably. For example, in the case of setting the fire source near other source(s)[6] or near a vertical wall[7], the flame and plume from the source are merging each other or rising along the wall, and the flame tip height is higher than that in free boundary. This behavior would be caused by the variation of combustion character due to the reduction of air entrainment and the pressure difference between wall side of flame and free boundary side.

As one of the cases that the air entrainment is restricted, the properties of flame and plume from a fire source, which is in a corner of vertical walls, has been investigated by some researchers. Hasemi and Tokunaga[8], Kokkala[9], and Tran and Janssens[10] studied the flame tip height and the buoyant plume properties using a square fire source set in a corner of vertical walls. They basically defined the flame tip height as a function of $\mathrm{Q}^{*}$ and they made the flame height correlations by using the concept of the virtual fire source. They focused on the heat flux to the wall surface, so that physical discussions about the corner flame/plume behavior have not been considered sufficiently. Cheng and Saito[11] studied on the fire induced flow patterns in a corner. They visualized the stream lines of the induced flow using particles illuminated by a laser sheet. Saito[12] carried out the measurement of flame height from a square pool fire source set in and near a corner, but he did not establish any correlation. Most researchers listed above have observed the extension of flame height, and they have pointed out this phenomenon is caused by reduction of air entrainment into diffusion flame[13]. However physical data for air entrainment and consideration of the effect of walls on air entrainment are not enough to establish a fire model.

In this study, to clarify the effect of air entrainment on flame/plume behavior and on combustion condition, systematic experiments are carried out for the case that the fire source is placed in and near a corner, as the parameters shown in below are varied. The characteristic diameter of the fire source, the rate of heat release from the source and the position of the source near a corner of walls are adopted as the experimental parameters. The flame tip heights under the parameter conditions are observed, and temperatures and upward velocities near a corner are measured. The relationship between flame behavior and air entrainment estimated based on the experimental data is discussed.

\section{EXPERIMENT}

(1) Corner Model and Measurement Equipment

FIGURE 1 shows the outline of the experimental apparatus used in this study. The corner model consisted of two walls of $3 \mathrm{~m}(\mathrm{H})$ $\times 1.7 \mathrm{~m}(\mathrm{~W})$. The material for walls and floor was ceramic fiber boards of $25 \mathrm{~mm}$ thickness.

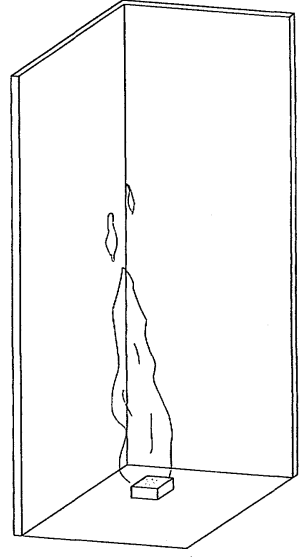

FIGURE 1 Outline of experimental apparatus. 
Sheathed K-type thermocouples and bi-directional Pitot tube - manometer systems were used to measure temperature and upward velocity, respectively. The horizontal spacing of measuring points was $0.05 \mathrm{~m}$ near a corner and $0.1 \mathrm{~m}$ far from a corner. The measuring heights corresponded to the flame region of each condition.

\section{(2) Experimental Parameters}

As the fire source, three square gas diffusion flame burners of $0.05 \mathrm{~m} \times 0.05 \mathrm{~m}, 0.1 \mathrm{~m} \times$ $0.1 \mathrm{~m}$, and $0.2 \mathrm{~m} \times 0.2 \mathrm{~m}$ were used, and propane gas was used as a fuel. Heat release rate from the fire source, $\mathrm{Q}^{*}$, was adjusted to $1.5-22.5 \mathrm{~kW}$ for each burner size. Flame tip height behavior was observed for the different combinations of burner size and heat release rate. These combinations are listed in TABLE 1. For the combinations marked by " $\uparrow$ " in this table, not only the observation of flame height, but also the measurement of temperature and upward velocity were conducted. The range of $\mathrm{Q}^{*}$ for the experiment series was from about 0.1 to 25 .

TABLE I Combinations of burner size and heat release rate used for experiments

\begin{tabular}{c|l}
\hline Burner size $[\mathrm{m}]$ & \multicolumn{1}{|c}{ Heat release rate $[\mathrm{kW}]$} \\
\hline $0.05 \times 0.05$ & $4.5,7.5,15.0$ \\
$0.1 \times 0.1$ & $1.5,3.0,4.5 \uparrow, 6,7.5 \uparrow, 15 \uparrow, 22.5$ \\
$0.2 \times 0.2$ & $2.25,4.5,7.5,15,22.5$ \\
\hline
\end{tabular}

When the fire source was placed near a corner, the edge line of the burner was set parallel to the wall surface. FIGURE 2 shows the plan view of the burner set up, where $S_{1}$ and $S_{2}$ in this figure are the separation distances from a burner to each respective wall surfaces. The ratios of $S_{1}$ and $S_{2}$ as the experimental parameter were $\mathrm{S}_{1}: \mathrm{S}_{2}=1: 0$ (Case (a), $\mathrm{S}_{2}=0$, that is, one burner edge is always attached to the wall surface), $\mathrm{S}_{1}: \mathrm{S}_{2}=1: 1 \quad$ (Case (b)), and $\mathrm{S}_{1}: \mathrm{S}_{2}=1: 2 \quad$ (Case (c)). The distance parameters from a burner edge to the wall surface are listed in TABLE 2, and where D is a characteristic diameter of the fire

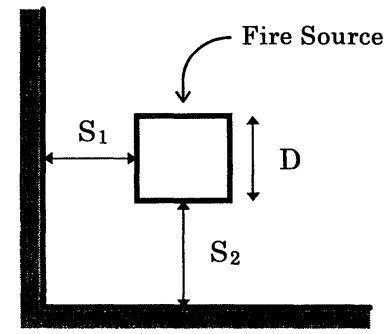
source.

TABLE 2 Distance parameters from burner to wall

\begin{tabular}{c|c|c}
\hline & $\mathrm{S}_{1}: \mathrm{S}_{2}$ & $\mathrm{~S}_{1} / \mathrm{D}$ \\
\hline \hline Case(a) & $1: 0$ & \multirow{2}{*}{$0.0,0.2,0.5,1.0,2.0,3.0,4.0,8.0$} \\
\hline Case(b) & $1: 1$ & \\
\hline Case(c) & $1: 2$ & $0.0,0.2,0.5,1.0,1.5,2.0,4.0$ \\
\hline
\end{tabular}


(3) Observation and Definition of Flame Height

The observation of flame height is conducted using a conventional video tape recorder system. Three hundred successive images of instantaneous flame tip heights recorded by the system were processed. The average of those images was defined as the flame tip height, $L_{f}$.

\section{RESULTS AND DISCUSSION}

In this paper, the results of Case (b) is dealt as a typical case.

\section{(1) Properties of Flame and Upward Flow}

FIGUREs 3(A)-(C) are the typical isothermal contour maps for the vertical section of $45^{\circ}$ angle from each wall surface (example : a-a' section), and for the horizontal plans of above and below the mean flame tip height, $\mathrm{L}_{\mathrm{f}}$. FIGURE 3(A) is illustrated for the case of $\mathrm{S} / \mathrm{D}=0$, that is, the burner is placed in a corner, $3(\mathrm{~B})$ for $\mathrm{S} / \mathrm{D}=0.5$, and $3(\mathrm{C})$ for $\mathrm{S} / \mathrm{D}=2.0$, respectively. In these cases the $0.1 \mathrm{~m} \times 0.1 \mathrm{~m}$ burner was adjusted to give $\dot{Q}=15 \mathrm{~kW}$. For the case of $S / D=0$, the thermal flow rises along a corner from the base, and the high temperature region extends higher and narrower than that obtained for $\mathrm{S} / \mathrm{D}=2.0$.

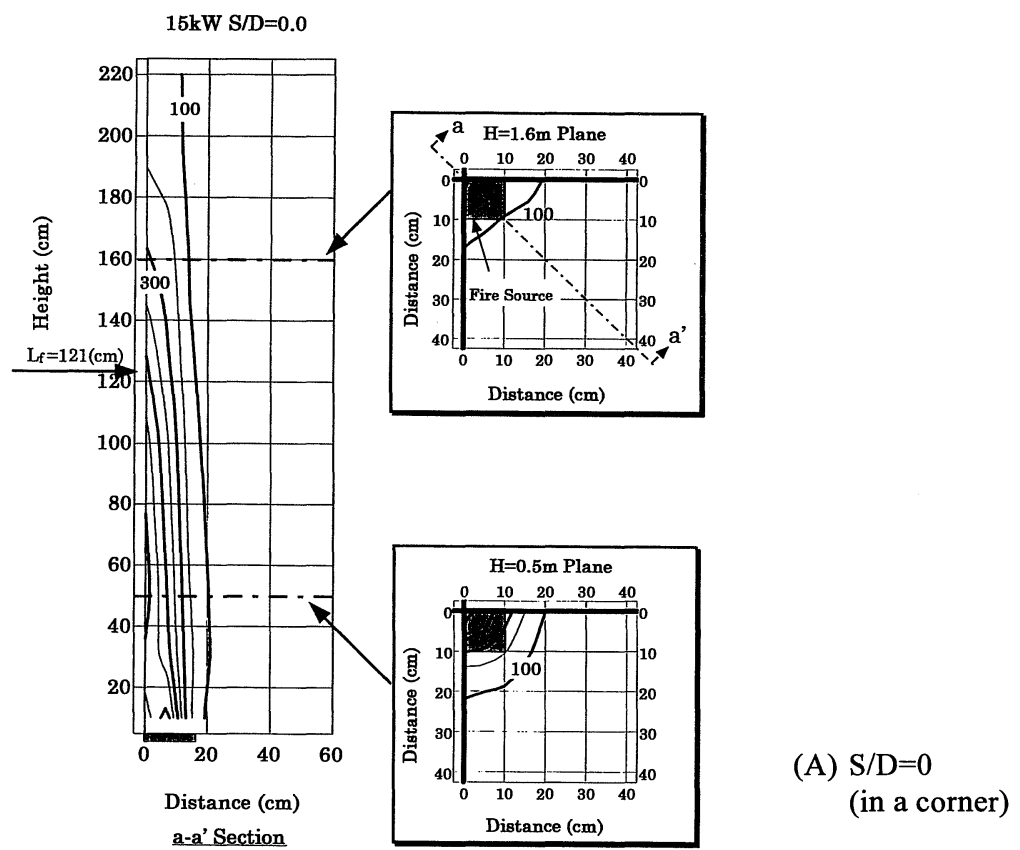

FIGURE 3 Isothermal contour maps for vertical section of $45^{\circ}$ angle from each wall and horizontal plans of above and below the mean flame height using a $0.1 \mathrm{~m} \times 0.1 \mathrm{~m}$ burner at $15 \mathrm{~kW}$. Comparisons among $\mathrm{S} / \mathrm{D}=0, \mathrm{~S} / \mathrm{D}=0.5$ and $\mathrm{S} / \mathrm{D}=2.0$. 


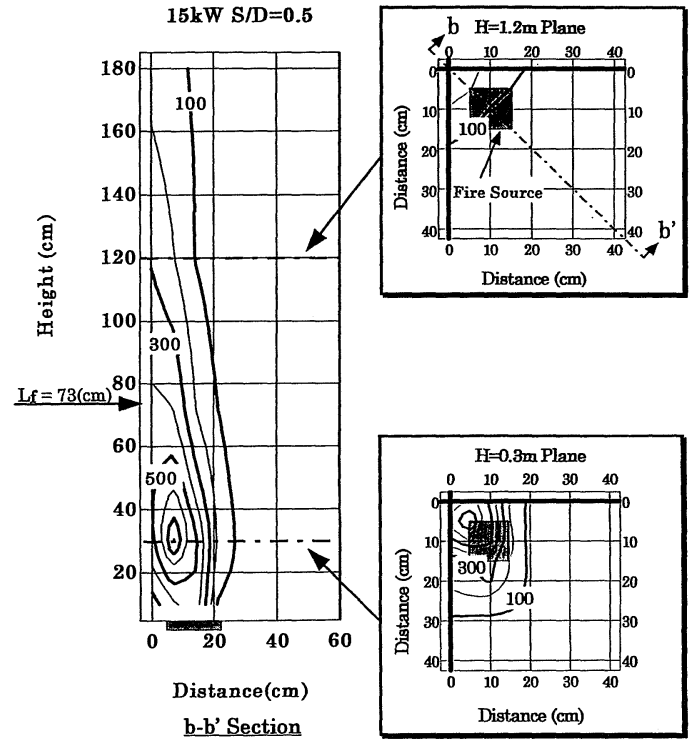

(B) $\mathrm{S} / \mathrm{D}=0.5$

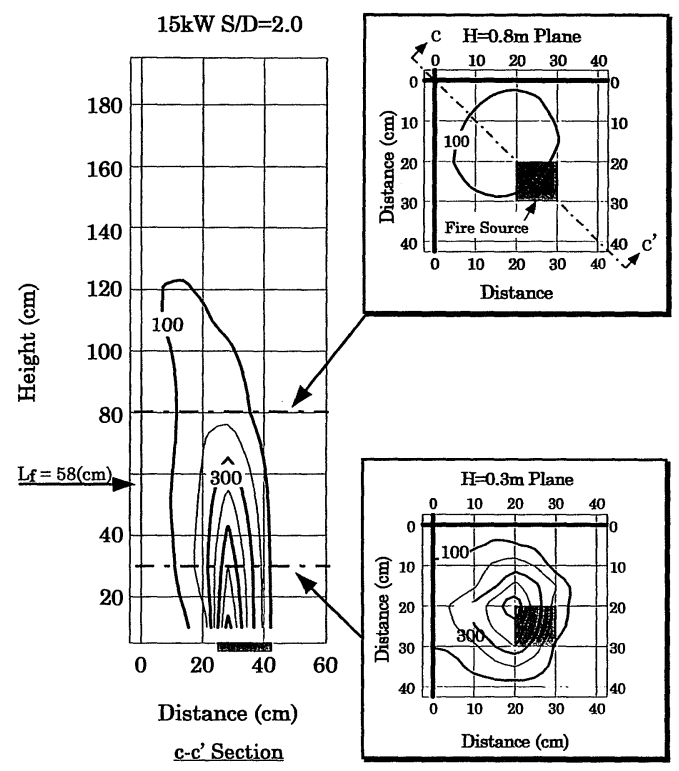

(C) $\mathrm{S} / \mathrm{D}=2.0$

FIGURE 3 Continued. 
Further, in the case of $\mathrm{S} / \mathrm{D}=0$ and 0.5 , thermal flow spreads horizontally along both side walls at the height above $\mathrm{L}_{\mathrm{f}}$ so that the shapes of the isothermal lines for horizontal plan look like triangles. On the other hand, those for $\mathrm{S} / \mathrm{D}=2.0$ looked like equicentered circles.

The variations of temperature and upward velocity as a function of height are shown in FIGUREs 4 and 5, respectively. The data in these figures are the maximum excess temperature and velocity for each measuring height, and the correlation established by McCaffrey[14] is superimposed as a reference. FIGURE 4 shows the vertical extension of high temperature region for $S / D=0$, and the tendency for $\mathrm{S} / \mathrm{D}=0.5$ approaches the behavior obtained for $S / D=0$ with increase of height. For $S / D=2.0$, although the behavior is agree with the correlation of free boundary fire, temperature reduction becomes moderate and approaches that of corner fire. Also it is found out from FIGURE 5 the reduction of upward velocity with height is slight in the measuring range for the case of $\mathrm{S} / \mathrm{D} \leq 2.0$.

(2) Flame Tip Height

FIGURE 6 shows the typical results of dimensionless flame tip height, $\mathrm{L}_{\mathrm{f}} / \mathrm{D}$, from a fire source set in and near a corner as a function of dimensionless heat release rate, $Q^{*}$. The correlation obtained by Zukoski[1] for the free boundary condition is superimposed in this figure as a reference. It is shown from this figure that $L_{f}$ for $S / D=0$ is nearly twice as large as the free boundary condition, and that for $\mathrm{S} / \mathrm{D}=2.0$ is almost the same as the free boundary. In the case of $S / D=0.5$, the behavior for $Q^{*}<1$ agreed with the

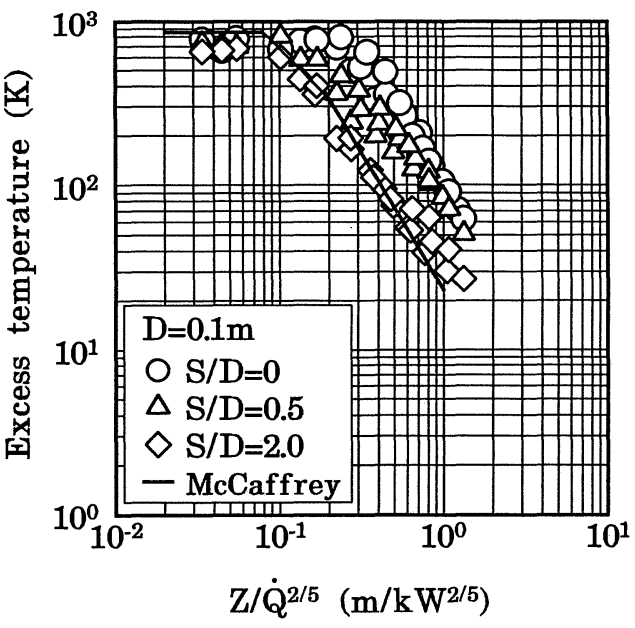

FIGURE 4 Variation of excess temperature as a function of height in the cases that a fire source is placed in and near a corner.

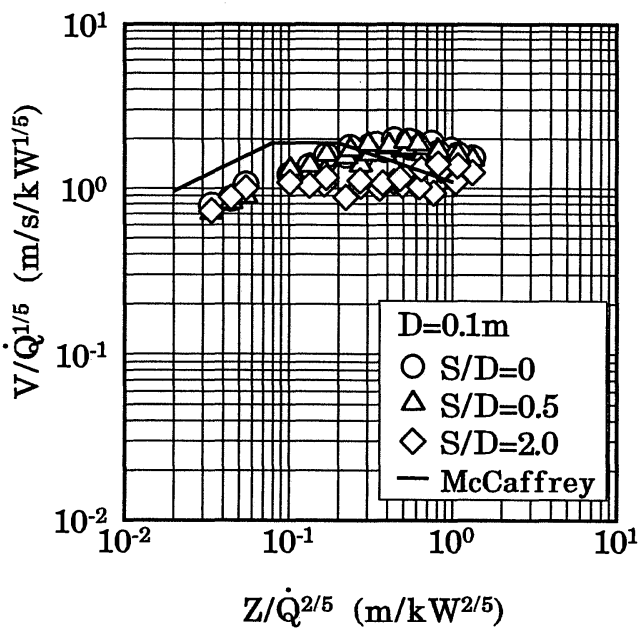

FIGURE 5 Variation of upward velocity as a function of height in the cases that a fire source is placed in and near a corner. 
correlation, but the value of $\mathrm{L}_{\mathrm{f}}$ departs from the correlation line and approaches the nature for $\mathrm{S} / \mathrm{D}=0$ with increasing of $\mathrm{Q}^{*}$. These results indicate that when the separation from a wall is more than twice of the characteristic diameter of the source, there is little effect of the wall on the flame height behavior. Furthermore, it is found that the effect of walls depends on the intensity and/or the scale of a fire source.

\section{(3) Plume Mass}

It is difficult to estimate the mass flow of fire plume from the measured data on upward velocity and temperature because the peripheral zone of plume is turbulent and gives no clear boundary from the surroundings. This is due to discontinuity of measuring points and turbulence of the plume. In this study, the boundary line of plume is defined applying "N\%" method as used for the decision of smoke layer boundary. Thus, the isothermal line of $15 \%$ of the maximum temperature for each measuring height is defined as the plume boundary: Then the plume mass flow, $\dot{\mathrm{m}}_{\mathrm{p}}$, at the measuring height is evaluated by integrating $\rho \mathrm{V}(\mathrm{V}$ : measured upward velocity $[\mathrm{m} / \mathrm{s}], \rho$ : density of gas at the point measuring $\mathrm{V}\left[\mathrm{kg} / \mathrm{m}^{3}\right]$ ) over the area surrounded by the boundary line. The evaluated values from the experimental data on free boundary agreed with the correlation for $\dot{\mathbf{m}}_{\mathrm{p}}$ obtained by Zukoski[1], except for the continuous flame region, as shown in FIGURE 7.

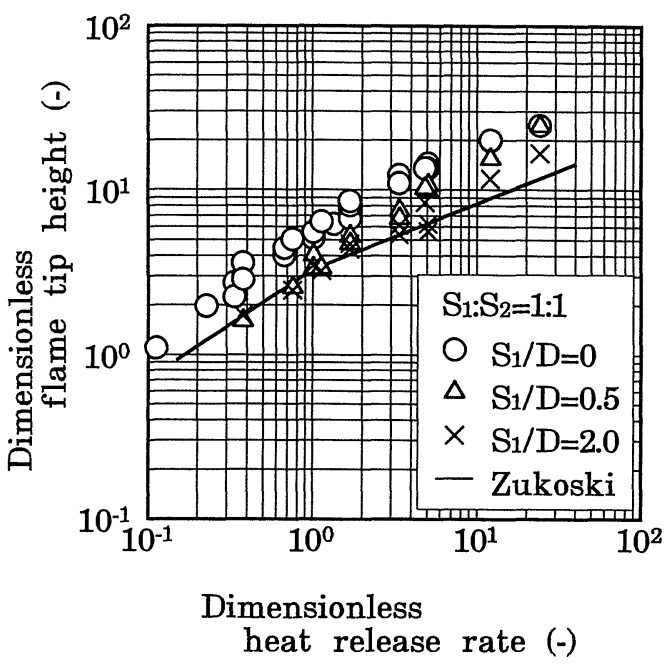

FIGURE 6 Correlation of dimensionless flame tip height with dimensionless heat release rate for each separation condition.

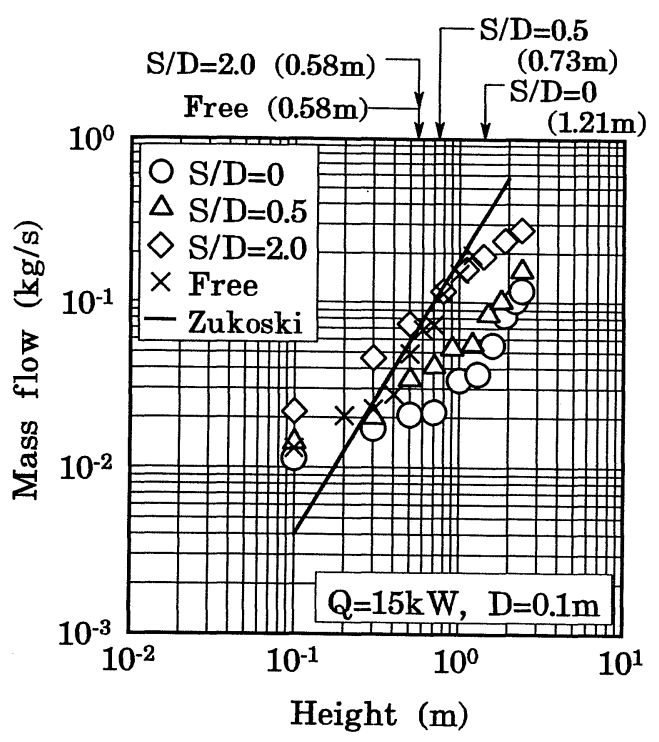

FIGURE 7 Variation of plume mass flux as a function of height in the cases that a fire source is placed in and near a corner. 
FIGURE 7 shows the increase of $\dot{\mathrm{m}}_{\mathrm{p}}$ with height and also $\mathrm{L}_{\mathrm{f}}$ for each separation condition in the case of $\dot{\mathrm{Q}}=15 \mathrm{~kW}$ and $\mathrm{D}=0.1 \mathrm{~m}$. It is clearly found that the slope of plotted data changes at $L_{f}$ for the case of $S / D=0$. In this case, although the rate of increase is similar to the free boundary condition above $\mathrm{L}_{\mathrm{f}}$, the rate of increase of $\dot{\mathrm{m}}_{\mathrm{p}}$ below $\mathrm{L}_{\mathrm{f}}$ is depressed. The tendency for $S / D=0.5$ similar to $S / D=0$, it is found the growth $\dot{\mathrm{m}}_{\mathrm{p}}$ of is restricted.

It is explained below that the growth of $\dot{\mathrm{m}}_{\mathrm{p}}$ with height is restricted when $\mathrm{S} / \mathrm{D}$ is relatively small. In the cases of $\mathrm{S} / \mathrm{D}=0$ and 0.5 , it appears that the area contributing air entrainment is smaller than those of $\mathrm{S} / \mathrm{D}=2.0$ and free boundary condition because the horizontal section of plume looks like triangular shape as shown in Figure 3(A) and (B), and in addition, two directions to entrain air are blocked by walls. Nevertheless, at much higher region, where the effect of walls on plume flow is not negligible, even data of $\mathrm{S} / \mathrm{D}=2.0$ deviate from the free boundary behavior.

FIGURE 8 indicates the ratio of $\dot{\mathrm{m}}_{\mathrm{p}}$ at $\mathrm{L}_{\mathrm{f}}$ to fuel supply rate for each experimental condition as a function of heat release rate from a fire source.

From this figure it is found the ratio is smaller when S/D is smaller and heat release rate is larger. It means mass of air entrained per unit fuel becomes less as flame extension is larger.

The variation of peripheral length in horizontal section, $\ell_{\mathrm{p}}$, as a function of height is shown in FIGURE 9. This length can be regarded as the periphery where surrounding air entrains. It is clear that $\ell_{\mathrm{p}}$ of each height for $\mathrm{S} / \mathrm{D}=0$ and 0.5 is smaller than that for $S / D=2.0$, especially at lower region. On the other hand, in the case of $S / D=2.0$, though the horizontal area of plume for the lower region varies greatly, the growth of plume is suppressed above the height where the boundary line reaches a wall surface. 
(4) Air Entrainment

When it is assumed that the mass of plume is increased by air entrainment through a periphery, $\ell_{\mathrm{p}}$, between $\mathrm{Z}$ and $\mathrm{Z}+\Delta \mathrm{Z}$ ( $\mathrm{Z}$ : height), mass flux for air entrainment, $\dot{\mathbf{m}}_{\mathrm{e}}^{\prime \prime}$ $\left[\mathrm{kg} / \mathrm{s} \cdot \mathrm{m}^{2}\right]$, can be described as follow,

$$
\dot{\mathrm{m}}_{\mathrm{e}}^{\prime \prime}=\frac{\Delta \dot{\mathrm{m}}_{\mathrm{p}}}{\Delta \mathrm{Z}} \cdot \frac{1}{\ell_{\mathrm{p}}}
$$

where $\Delta \dot{\mathrm{m}}_{\mathrm{p}}$ is an increment of plume mass between $\mathrm{Z}$ and $\mathrm{Z}+\Delta \mathrm{Z}$. The relationship between the measured maximum upward velocity and the calculated entrainment mass flux is shown in FIGURE 10 . The values of $\dot{\mathbf{m}}_{\mathrm{e}}^{\prime \prime}$ are clustered around $0.1 \mathrm{~kg} / \mathrm{s} \cdot \mathrm{m}^{2}$, and is not dependent on the maximum upward velocity.

In the case that a fire source is placed near a corner, it is found that the horizontal growth of plume and the reduction of temperature and upward velocity against height are slight. Moreover, it appears the exchange of combustion gases with fresh air is restricted for flame/plume flow along a corner. From these discussions, it is expected that flame/plume behavior along a corner is dependent on the turbulence of the flow. To investigate the degree of turbulence for flame/plume flow along and near a corner, we consider a relative Reynolds number, $\mathrm{Re}^{*}$, at any height, given as,

$$
\operatorname{Re}^{*}=\frac{\ell_{\mathrm{p}} \cdot \mathrm{V}}{v}
$$

\section{FIGURE 11}

Variation of the relative Reynolds number as index on turbulence of flame/plume flow.

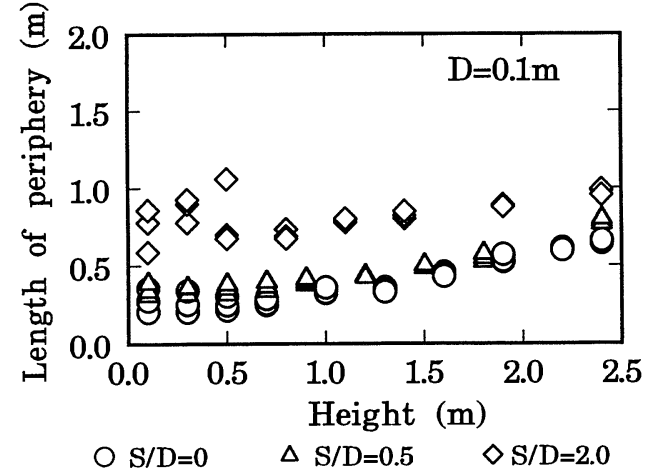

FIGURE 10 Relationship of mass flux of air entrainment per unit area with characteristic upward velocity in the cases of a fire source near a corner. 
where $\mathrm{V}$ is maximum upward velocity at the height and $v$ is a kinematic viscosity at the plume boundary. Typical calculated results for $\mathrm{Re}^{*}$ are plotted against height in FIGURE 11. This figure shows that the results for $S / D=2.0$ resemble the nature of free boundary fire at lower region. However, the results of $\mathrm{Re}^{*}$ for this case transfer to the nature of corner fire with height. In other words, it appears that the effect of walls on a plume flow becomes comparably large with height, and the turbulence of flow is reduced. For the case that a fire source is placed nearer a corner, although $\mathrm{Re}^{*}$ increases gradually with height, the value is much smaller than the results of free boundary condition.

\section{CONCLUSIONS}

The experimental study on flame height and fire plume behavior in the case that a fire source is in and near a corner of walls was carried out. Corner fire could be defined by a few characters, that is, reduction of upward velocity with height is slight, horizontal growth of plume is moderate, and height of flame is tall compared with free boundary fire. Also it is found that air entrainment mass flux for corner fire is almost constant against upward velocity. These results confirm that mixing of fuel with surrounding air is restricted and laminarization of plume flow is occurred along vertical walls.

\section{Acknowledgment}

The authors are deeply grateful to Mr. Tatsuya Kawasaki, Miss Masami Kihara, and Miss Chieko Yoneyama, undergraduate students of Science University of Tokyo, for their assistance in the experiments.

\section{REFERENCES}

[1] Zukoski, E., Kubota, T. and Cetegen, B., "Entrainment in Fire Plume", Fire Safety J., Vol.3, p.107-121, (1980/81).

[2] Cox, G. and Chitty, R., "Some Source-Dependent Effects of Unbounded Fires", Combustion and Flame, Vol.60, pp.219-232, (1985).

[3] Thomas, P.H., "The Size of Flames from natural Fires", Proceedings 9th symposium on Combustion, pp.844, The Combustion Institute, (1963).

[4] Heskestad, G., "Virtual Origins of Fire Plume", Fire Safety J., Vol.5, pp.109-201, (1983).

[5] Stewart, F.R., "Prediction of the height of turbulent diffusion flames", Combustion Science and Technology, Vol.2, pp.203-212, (1970).

[6] Sugawa, O., Satoh, H. and Oka, Y., "Flame Height from Rectangular Fire Sources Considering Mixing Factor", Proceedings of the Third International Symposium on Fire Safety Science, pp.435-444, Elsevier Applied Science, (1991).

[7] Sugawa, O. and Takahashi, W., "Fire Height Behavior from Multi-fire Sources", Fire and materials, Vol.17, pp.111-117, (1993).

[8] Hasemi, Y. and Tokunaga, T., "Some Experimental Aspects of Turbulent Diffusion Flames and Buoyant Plumes from Fire Sources against a Wall and in a Corner of Walls", Combustion Science and Technology, Vol.40, pp.1-7, (1984). 
[9] Kokkala, M., "Characteristics of a Flame in an Open Corner of Walls", Proceedings of INTERFLAM'93, pp.13-24, (1993).

[10] Tran, H. and Janssens, M., "Modeling the Burner Source used in the ASTM Room Fire Test", J. of Fire protection Eng., Vol.5, pp.53-66, (1993).

[11] Cheng Qian and Saito, K., "Fire-Induced Flow along the Vertical Corner wall", Proceedings of First Asian Conference on Fire Science and Technology, International Academic Publishers, pp.257-262, (1992).

[12] Saito, F., "Study on Fire Risk of Lining Materials", Proceedings of Annual Symposium of Architectural Institute of Japan, pp.13-16, (1964) (in Japanese).

[13] Drysdale, D., An Introduction to FIRE DYNAMICS, pp.135-136, John-Wiley \& Son, 1985.

[14] McCaffrey, B., "Purely Buoyant Diffusion Flames : Some Experiment Results", NBR-IR 79-910, (1979). 
